\title{
STRATEGI KESANTUNAN DAN PELANGGARAN PRINSIP KERJASAMA DALAM TALKSHOW RUMPI (NO SECRET) DI TRANS TV (TINJAUAN PRAGMATIK)
}

\author{
Maria Ana Widyaningrum ${ }^{1}$, Sumarlam ${ }^{2}$, Sri Marmanto ${ }^{2}$ \\ ${ }^{1}$ Magister Linguistik Pascasarjana, Universitas Sebelas Maret \\ ${ }^{2}$ Universitas Sebelas Maret, Surakarta, Indonesia \\ ${ }^{1}$ anadumilah@gmail.com
}

\begin{abstract}
This study discusses politeness strategy happened between host and interviewee. As public figure, politeness strategy is important to keep and protect 'face' of related person from being threatened. The method used in study is method of descriptivequalitative research. Its data is spoken data from Rumpi (No Secret) episode in Trans Tv. Taking sample is done by purposive sampling. Providing data technique is done by free listening and involved conversation technique, recording technique, and writing technique. The result of the study shows that conversation performed by host and interviewee in Rumpi (No Secret), in speaking politeness strategy of host, was more strictly, host gave shympathy to interviewee, host often joked to make ice breaking, host also often gave close question model. Breaking cooperative principle done by interviewee broke one maxim, there were quantity maxim, quality maxim, manner maxim, and relevant maxim; broke two maxims, which were quantity and manner maxim, quality and manner maxim, quantity and relevant maxim, quantity and quality maxim, relevant and manner maxim; broke three maxims, which were quantity, relevant, and manner maxim; quantity, quality, and manner maxim; quality, relevant, and manner maxim. There are 18 implicators caused by breaking cooperative principle, which are unready interview implicators, blaming, critizicing, informing, revealing, sadness, stating, prohibiting, disclaiming, joking, mocking, proving, explaining, being confused, carefully answering, evaluating, being annoyed, suspecting, confirming.
\end{abstract}

Keyword: politeness strategy, cooperative principle, implicator

\section{PENDUHULUAN}

Salah satu wujud interaksi yang dilakukan oleh manusia adalah berbicara dalam sebuah percakapan. Sebagai makhluk sosial, manusia melakukan percakapan untuk membentuk interaksi antar individu. Percakapan juga dilakukan untuk memelihara hubungan sosial manusia itu sendiri. Dalam percakapan, kesantunan merupakan aspek penting dalam kehidupan untuk menciptakan komunikasi yang baik antara penutur dan lawan tutur kata santun mempunyai makna yang sangat berbeda dengan kata sopan, meskipun sebagian masyarakat menganggapnya sama. kata sopan mempunyai makna untuk menunjukkan rasa hormat terhadap mitra tutur, sedangkan 
kata santun mempunyai makna memperhalus ujaran atau tuturan yang dapat mengancam muka dan harga diri (Pramujiono: 2011).

Salah satu pakar yang membahas kesantunan berbahasa adalah Brown dan Levinson (1987), menurutnya strategi kesantunan digunakan oleh penutur untuk menghindari tindak pengancaman terhadap muka lawan tutur. Dalam proses komunikasi, kadang-kadang seorang peserta komunikasi mengucapkan ujaran-ujaran yang menyebabkan dirinya atau orang lain kehilangan muka. Strategi kesantunan digunakan untuk lebih menghargai orang lain maupun diri sendiri. Dalam komunikasi sehari-hari kita tidak dapat setiap saat menyampaikan tuturan dengan cara yang santun, hal tersebut kemungkinan akan menyakiti perasaan lawan tutur. Tindak pengancaman muka tersebut oleh Brown dan Levinson (1987) disebut dengan FTA (Face Threatening $A c t$ ). Konsep 'muka' bagi mereka sangat mutlak untuk dijaga, sehingga seorang peserta komunikasi pada suatu saat tertentu merasa perlu menggunakan strategi tertentu untuk memperkecil kadar ancaman yang terkandung dalam ujarannya, dan dapat menyebabkan dirinya atau orang lain kehilangan muka.

Dalam sebuah acara talkshow yang disiarkan secara langsung, muka positif memegang peran penting karena narasumber atau orang yang diberikan pertanyaan mempunyai kesempatan yang sangat besar untuk kehilangan muka positif. Dalam merespon dan mengajukan pertanyaan, mereka berkecenderungan menggunakan strategi tertentu sebagai usaha untuk menjaga citra diri dan citra lawan tutur agar tetap baik dihadapan masyarakat umum, serta menjaga agar proses komunikasi tersebut dapat berjalan dengan lancar dan harmonis.

Dari segi pragmatik selain strategi kesantunan, sebuah percakapan memiliki beberapa prinsip yang harus dipenuhi oleh para peserta tuturnya agar percakapan yang dilakukan dapat berjalan dengan baik dan koheren. Salah satu diantaranya adalah prinsi kerjasama. Kerjasama merupakan hal yang perlu dimiliki oleh penutur dan mitra tuturnya. Kerjasama yang dimaksud disini adalah kontribusi peserta tutur dalam memberikan informasi sesuai dengan apa yang dibutuhkan lawan tutur, yaitu informasi yang cukup dan relevan dengan pembicaraan yang sedang berlangsung.

Dalam sebuah komunikasi tidak semua tuturan mematuhi prinsip kerjasama, ada kalanya sebuah tuturan atau percakapan melanggar prinsip-prinsip kerjasama tersebut. Terkadang mitra tutur menanggapi atau memberikan pertanyaan yang tidak 
sesuai atau tidak relevan dengan permasalahan yang dimaksudkan oleh penutur. Ada kalanya mitra tutur yang memberikan tanggapan atau jawaban yang berlebihan, memberikan informasi yang ambigu. Pelanggaran tersebut dapat terjadi karena adanya tujuan yang memang sengaja dilakukan peserta komunikasi.

Terjadinya pelanggaran prinsip kerja sama akan menimbulkan implikatur percakapan (Rustono, 1991: 82). Menurut Brown dan Yule "implikatur dipakai untuk memperhitungkan apa yang disarankan atau apa yang dimaksud oleh penutur sebagai hal yang berbeda dari apa yang dinyatakan secara harafiah." (dalam Abdul Rani, Bustanul Arifin, Martutik, 2006: 170).

Berdasarkan penjelasan di atas, sangat menarik untuk meneliti secara ilmiah mengenai strategi kesantunan dan pelanggaran prinsip kerjasama yang muncul dalam acara Rumpi (No Secret) di Trans TV. Talkshow tersebut menghadirkan konsep menarik, kontroversi dan diminati oleh masyarakat indonesia. Tayangan berdurasi empat puluh lima menit tersebut terdiri dari empat sampai lima segmen untuk mengulik hal pribadi dari narasumber secara santai dan mendalam. Pertanyaan yang dilontarkan oleh pembawa acaranya bukan hanya gosip bintang tamu yang hadir, tetapi juga pertanyaan "nakal" yang tidak terpikirkan sebelumnya. Pembawa acara akan melontarkan pertanyaan-pertanyaan dengan menggunakan sudut pandang perempuan. Narasumber yang dihadirkan pun tidak hanya artis-artis kenamaan tanah air namun siapapun yang memberikan inspirasi kepada masyarakat, seperti pejabat atau orang biasa.

Suatu penelitian harus mempunyai tujuan yang jelas, sehingga hasil penelitiannya dapat diketahui. Tujuan penelitian ini adalah mendeskripsikan bagaimana strategi kesantunan yang digunakan untuk melindungi 'muka' seorang mitra tutur dan lawan tutur ketika berkomunikasi. Mendeskripsikan bagaimana bentuk pelanggaran prinsip kerjasama dalam tuturan narasumber sebagai konsekuensi digunakannya sebuah strategi kesantunan. Mendeskripsikan implikatur yang muncul berdasarkan pelanggaran prinsip kerjasama dalam talkshow Rumpi (No Secret) di Trans TV.

\section{TEORI DAN METODOLOGI}

Teori yang terdapat dalam penelitian ini digunakan untuk menganalisis jenis tindak tutur, strategi kesantunan yang digunakan oleh penutur dan mitra tutur, 
pelanggaran prinsip kerjasama serta implikatur yang muncul sebagai akibat adanya pelanggaran prinsip kerjasama. Berikut uraian teorinya.

\section{Teori Kesantunan}

Kesantunan berbahasa yang dikemukakan oleh Brown dan Levinson berawal dari konsep muka (face) yang pertama kali dikemukakan oleh Goffman (1967). Konsep ini erat sekali kaitannya dengan istilah sosial yang terdapat dalam masyarakat, yaitu 'kehilangan muka' yang berarti merasa malu atau terhina. Oleh karena itu, dalam setiap proses interaksi orang harus senantiasa saling menjaga muka.

Menurut Brown dan Levinson (1987), muka itu rawan terhadap ancaman yang timbul dari tindak tutur tertentu. Artinya, ada tindak tutur yang karena isi dan cara mengungkapkannya, menyebabkan muka terancam, baik muka penutur maupun muka petutur. Dikatakan oleh keduanya (1987: 65-68) bahwa konsep tentang muka ini bersifat universal, dan secara alamiah terdapat berbagai tuturan yang cenderung merupakan tindakan yang tidak menyenangkan yang disebut Face Threatening Acts atau tindakan yang mengancam muka dan singkat menjadi FTA.

Selain stategi kesantunan terdapat prinsip kerjasama sebagai acuan teori dalam penelitian ini. Chaer (2010:34) mengemukakan bahwa pertuturan akan berlangsung dengan baik apabila penutur dan lawan tutur dalam pertuturan itu menaati prinsipprinsip kerjasama. Dalam kajian pragmatik prinsip itu disebut maksim, yakni berupa pernyataan ringkas yang mengandung ajaran atau kebenaran. Grice (dalam Chaer, 2010:34) mengungkapkan bahwa di dalam prinsip kerjasama, seorang pembicara harus mematuhi empat maksim. Maksim tersebut harus ditaati oleh peserta pertuturan dalam berinteraksi, baik secara tekstual maupun interpersonal dalam upaya pelancarkan jalannya proses komunikasi. Keempat maksim percakapan itu adalah maksim kualitas (maxim of quality), maksim kuantitas (maxim of quantity), maksim relevansi (maksim of relevance) dan maksim cara (maxim of manner).

\section{Metode Penelitian}

Penelitian ini termasuk dalam jenis penelitian kualitatif yang bersifat deskriptif. Dalam Edi Subroto, (1992:5) metode kualitatif adalah metode metode pengkajian atau metode penelitian terhadap suatu masalah yang tidak didesain atau dirancang dengan menggunakan metode statistik. Pada penelitian kualitatif, paradigma atau perspektif 
yang digunakan adalah prespektif fenomenologis. Artinya, penelitian kualitatif berusaha memahami makna dari fenomena-fenomena, peristiwa-peristiwa, dan kaitannya dengan orang-orang atau masyarakat yang diteliti dalam konteks kehidupan dalam situasi yang sebenarnya.

Pendekatan yang digunakan dalam penelitian ini adalah pendekatan pragmatik, yaitu pendekatan yang mendasarkan diri pada reaksi atau tanggapan menurut lawan bicara (Edi Subroto, 2007:65). Pada penelitian ini, pendekatan pragmatik digunakan untuk menjawab permasalahan dan menginterpretasikan maksud suatu tuturan. Dengan mempertimbangkan konteks dan tuturannya penulis akan menganalisis strategi bertutur dan kesantunan berbahasa yang dilakukan oleh pembawa acara dan narasumber dalam talkshow Rumpi (No Secret) di Trans TV.

Pada penelitian ini, lokasi penelitian berasal dari laman situs website media massa elektronik www.youtube.com. Partisipan dalam penelitian ini adalah pembawa acara dan bintang tamu. Sumber data adalah asal dari data penelitian itu didapatkan. Data sebagai objek penelitian secara umum adalah informasi atau bahasa yang disediakan oleh alam yang dikumpulkan dan dipilih oleh peneliti (Sudaryanto, 1993:34). Adapun sumber data dalam penelitian ini adalah video acara talkshow Rumpi (No Secret) di Trans TV yang berisi percakapan atau kegiatan pertuturan antar partisipan. Data merupakan bahan jadi penelitian, bukan bahan mentah penelitian. Data adalah semua keterangan seseorang yang dijadikan responden maupun yang berasal dari dokumen-dokumen, baik dalam bentuk statistik atau dalam bentuk lainnya guna keperluan penelitian. Adapun data dalam penelitian ini adalah tuturan-tuturan pembawa acara dan narasumber dalam talkshow Rumpi (No Secret) yang didalamnya terdapat strategi kesantunan dan pelanggaran prinsip kerjasama beserta konteks yang melingkupinya.

Dalam penelitian ini, pengambilan sampel yang digunakan adalah sampel bertujuan (purposive sample) dalam artian pengambilan sampel yang diarahkan pada sumber data yang dipandang memiliki data penting dan juga berkaitan dengan permasalahan yang sedang diteliti (Sutopo, 2002:36). Sampel dalam penelitian ini diambil secara selektif berdasarkan ciri, sifat-sifat, atau karakteristik yang sesuai dengan tujuan penelitian. Kriteria dalam menentukan pada penelitian ini, yaitu kriteria episode yang dipilih berdasarkan bintang tamu yang diundang dalam talkshow Rumpi (No 
Secret) di Trans TV sejak bulan Agustus 2015 sampai Maret 2016 berdasarkan profesi yang berbeda. Selain profesi, peneliti juga melihat jumlah viewer yang menyaksikan tayangan tersebut.

Metode pengumpulan data dalam penelitian ini adalah metode simak dengan teknik simak bebas libat cakap, teknik rekam dan teknik catat. Dalam teknik simak libat bebas cakap, peneliti tidak dilibatkan secara langsung untuk ikut menentukan pembentukan dan permunculan calon data kecuali hanya sebagai pemerhati saja, pemerhati terhadap calon data yang terbentuk dan muncul dari peristiwa kebahasaan yang berada diluar dirinya (Sudaryanto, 1993:135). Ketika teknik simak bebas libat cakap digunakan, sekaligus dapat dilakukan pula perekaman dengan menggunakan alat perekam. Setelah data dikumpulkan melalui teknik simak libat bebas cakap dan teknik rekam, data ditranskripsikan dengan menggunakan teknik catat. Teknik catat adalah teknik menjaring data dengan mencatat hasil penyimakan data pada kartu data (Tri Mastoyo Jati Kesuma, 2007).

Tahap analisis data dilakukan setelah data dikumpulkan dan diklasifikasi. Penelitian ini menggunakan pragmatik sebagai ancangannya. Dalam menganalisis data, peneliti menggunakan analisis pragmatik yaitu analisis bahasa berdasarkan pada sudut pandang pragmatik (Rustono, 1999). Analisis dalam penelitian ini menggunakan metode padan pragmatis. Metode padan pragmatis adalah metode yang dipakai untuk mengkaji atau menentukan identitas satuan lingual tertentu dengan memakai alat penentu yang berada diluar bahasa (Sudaryanto, 1993). Metode padan pragmatis ini diterapkan dengan pendekatan kontekstual yang mengacu pada tuturan-tuturan yang didalamnya terdapat strategi kesantunan dan pelanggaran prinsip kerjasama dalam talkshow Rumpi (No Secret) di Trans TV. Teknik merupakan penjebaran metode yang ditentukan oleh alat yang dipakai untuk menganalisis data. Dalam Leech (Edisi terjemahan oleh M.D.D. Oka, 1993) menjelaskan bahwa strategi pemecah masalah oleh penutur dapat dilihat sebagai sebuah bentuk analisis cara-tujuan (means-end). Penutur bertugas menggunakan cara yang tepat agar tujuan tuturannya dapat tercapai dengan baik. Analisis cara-tujuan pada umumnya diterapkan pada penggunaan bahasa secara komunikatif. Dalam menganalisis tuturan akan dikaitkan dengan konteks yang telah ditunjukkan. Setelah itu tuturan diidentifikasi dengan menunjukkan penanda lingualnya dan disebutkan siapa yang menuturkan, kepada siapa, dan apa tujuannya. Setelah itu 
peneliti mendeskripsikan tuturan yang telah diidentifikasi dengan diperkuat melalui penanda lingual tersebut.

\section{HASIL PENELITIAN DAN PEMBAHASAN}

Brown dan Levinson juga menjelaskan bahwa dalam penggunaan FTA dipengaruhi oleh tiga faktor sosial, yaitu kekuasaan (power), jarak sosial (distance) dan tingkat pembebanan (ranking of imposition). Agar tuturan tetap santun, Brown dan Levinson membaginya dalam strategi kesantunan yaitu strategi kesantunan langsung tanpa basa basi (bald on record strategy), strategi kesantunan positif (positive politeness strategy), strategi kesantunan negatif (negative politeness strategy), strategi tidak langsung (off record) dan strategi diam.

\subsection{Tuturan Pembawa Acara Lugas}

Temuan dari hasil penelitian menunjukkan adanya tuturan pembawa acara dalam mencari informasi secara lugas, hal ini digunakan untuk memaksimalkan tuturannya. Temuan ini sesuai dengan teori yang dikemukan oleh Brown dan Levinson (1987) Seandainya penutur memutuskan memilih membuat tuturannya secara on record maka penutur masih harus menentukan apakah penutur harus membuat tuturan secara lugas tanpa usaha menyelamatkan muka lawan 'badly without redress', ataukah dengan pertimbangan langkah-langkah penyelamatan muka lawan 'redressive action'. Melakukan tindakan secara lugas, tanpa usaha penyelamatan muka berarti melakukan tindakan tersebut dengan cara yang paling langsung, jelas, tegas, dan ringkas.

Konteks Tuturan: Tuturan ini terjadi saat Feni Rose menanyakan hadiah apa saja yang diberikan oleh Charlie untuk Rere Regina. Kabarnya Rere menerima beberapa barang-barang dari Charlie yang membuat istri Charlie merasa marah.

\section{Bentuk Tuturan:}

Rose : o...gitu. kena damprat juga. Yang dapet mobil siapa? Kamu apa dia?

Rere : Ngga tau. Aku ngga pernah dapet apa-apa dari Charlie. Ya Allah...

Rose : Oke. Ngga pernah dapet apa-apa? Tas ngga? Jam tangan?

Rere : Kalau tas, cuma tas-tas biasa doang gara-gara valentine. (37/28 Sept 2015/RNS)

Pada data di atas digolongkan dalam jenis tindak tutur Asertif (menyebutkan) hal ini terlihat dari tuturan Feni Rose yang menyebutkan beberapa barang yang kabarnya diberikan oleh Charlie kepada Rere Regina. Indikasi kesantunan pada data di atas dapat dilihat pada tuturan Rose "Oke. Ngga pernah dapet apa-apa? Tas ngga? Jam 
tangan ngga?" secara langsung menyebutkan barang-barang apa saja yang diberikan oleh Charlie. Tuturan Feni Rose tersebut termasuk dalam strategi langsung tanpa basa basi ini digunakan oleh Feni Rose untuk mengetahui kebenaran berita tentang isu tuduhan orang ketiga perusak rumah tangga Charlie dan istrinya. Hal ini menyebabkan pengancaman muka untuk lawan tutur, sehingga Rere melakukan sanggahan untuk melindungi muka atas tuturan penutur. Sanggahan yang dilakukan oleh Rere Regina terdapat pada strategi kesantunan negatif dengan sub strategi ke dua yaitu menggunakan pagar. Penggunaan strategi ini digunakan Rere untuk melindungi citra dirinya yang tidak mau dipandang sebagai wanita yang gampang menerima barang pemberian dari suami orang.

\subsection{Pembawa Acara Memberikan Simpti kepada Narasumber}

Temuan kedua pada strategi kesantunan adalah host memberikan simpati kepada narasumber. Hal ini ditemukan penulis pada strategi kesantunan dengan substetegi memberikan perhatian kepada lawan tutur, melebihkan minat terhadap lawan tutur, meningkatkan terhadap lawan tutur, menghindari ketidakcocokan. Temuan ini sesuai dengan teori yang dikemukakan Brown dan Levinson (1987). Pada penelitian ini pembicara memberikan simpati kepada narasumber dengan memperhatikan aspek-aspek situasi yang sedang dialami oleh narasumber.

Konteks Tuturan: Tuturan ini terjadi saat Risty menceritakan bagaimana Stuart yang sebenarnya tidak mengharapkan kelahiran anak yang dikandung Risty.

\section{Bentuk Tuturan:}

Rose : Betul dia tidak diharapkan?

Risty : Ngga. Jadi itu mungkin alasan kenapa ngga segampang itu untuk membiarkan dia ketemu sama Arka. Selain dia nyakitin aku terutama mama, dia sempet menyesali bahwa aku hamil dan itu sakit banget. Buat aku sih bener-bener sakit sekali karna pada saat hamil aja tuh udah muntah, udah pening udah segala macem trus denger dia dengan enaknya ngomong "saya itu nyesel bla..bla..dikamu sampai kamu hamil" dan itu tuh didengarkan sama asisten aku dua-duanya, aku lagi perjalanan ke Surabaya dimana aku tetep bekerja keras disaat aku harus bedrest dan dia hanya di rumah pada saat itu dan dia malah bisa-bisanya ngomong seperti itu.

(69/4 Mar 2016/RNS)

Tuturan direktif (bertanya) dituturkan oleh Feni Rose. Tuturan direktif 'bertanya' digunakan pembawa acara untuk menanyakan lebih jauh tentang kebenaran 
berita yang menyatakan bahwa Stuart Colin tidak mengharakan anaknya lahir ke dunia. Strategi kesantunan terdapat dalam tuturan Feni Rose yang mengatakan "Betul dia tidak diharapkan?" merupakan penggunaan strategi kesantunan positif dengan sub-strategi ketiga yaitu meningkatkan ketertarikan terhadap lawan tutur. Dalam tuturan Feni Rose dapat dilihat bagaimana dia tertarik dengan pernyataan Risty tentang Stu yang tidak mengharapkan anaknya lahir. Hal ini memang menjadi daya tarik untuk Feni Rose dikarenakan kabar ini memang belum beredar di media. Risty baru membuka pernyataan itu saat dirinya menjadi bintang tamu dalam di acara Rumpi. Dalam menanggapi pertanyaan yang diajukan oleh pembawa acara, terdapat strategi kesantunan positif sub strategi ke tiga belas dalam tuturan Risty Tagor. Tuturan tersebut digunakan Risty untuk memberikan alasan kenapa Stuart Colin tidak menginginkan kelahiran anaknya. Strategi yang digunakan oleh Risty memiliki tujuan untuk melindungi muka atas pertanyaan yang diungkapkan oleh Feni Rose.

\subsection{Narasumber bertutur lebih mendominasi untuk melindungi muka.}

Temuan terakhir dari strategi kesantunan ini adalah narasumber yang bertutur lebih banyak, hal ini dilakukan oleh narasumber untuk melindungi muka positifnya didepan publik. Katika menerima pertanyaan dan ancaman, narasumber memberikan informasi yang dari yang dibutuhkan oleh pembawa acara. Pada penelitian ini, dengan memberikan informasi yang lebih, narasumber dapat menjelaskan kebenaran menurutnya.

Konteks Tuturan: tuturan ini terjadi saat Feni Rose menanyakan kepergian Umi Ima pasca kasus perceraiannya dengan Koko Liem. Umi Ima meninggalkan Koko Liem ke Pal Merah yang jaraknya memang jauh dari kediaman Koko Liem yang berada di Cibubur.

\section{Bentuk Tuturan:}

Rose : Pergi kemana?

Koko : Pergi ke rumah si A di Pal Merah, Koko kan di Cibubur.

Rose : Terus kemudian?

Koko : Cibubur, Pal Merah kan sekitar dua puluh enam kilo Mbak.

Rose : dua puluh enam kilo. Berapa jam ya?

Koko : Ya kalau macet satu jam ya. Nah, tahun dua ribu sembilan itu lah dia mulai tinggal disana mulai deket mulai deket sehingga rumah tangga saya dingin dan sebagainya sehingga adanya saya menikah lagi karna tidak mendapatkan nafkah batin hampir dua tahun.

(53/16 Des 2015/RNS) 
Pada tuturan di atas terjadi pelanggaran prinsip kerja sama. Dari percakapan ini dapat dilihat pelanggaran beberapa maksim kerja sama yaitu maksim kuantitas, maksim kualitas, dan maksim cara. Pelanggaran maksim kuantitas terjadi karena tuturan Koko Liem tersebuat secara kuantitas berlebihan. Kontribusi yang diberikan Koko Liem tidak sesuai dengan jawaban yang dibutuhkan, terlalu banyak. Pelanggaran maksim kualitas, dilihat dari tuturan Koko Liem "Ya kalau macet satu jam ya." Hal ini dapat dilihat dari sudut pandang kebenaran yang bersifat tidak mutlak dan mengatakan hal yang tidak disertai bukti sehingga percakapan tidak dapat diterima. Pelanggaran maksim cara karena tuturan Koko Liem terlalu bertele-tele sehingga membingungkan penutur dalam mengambil kesimpulan atas jawabannya. Namun selain melanggar, tuturan Koko Liem juga memenuhi maksim lain dari prinsip kerja sama yaitu maksim relevan. Memenuhi maksim relevan karena ada sebagian jawaban Koko Liem yang sesuai dengan pertanyaan yang diberikan oleh pembawa acara.

\section{SIMPULAN}

Berdasarkan hasil analisis dan pembahasan dapat disimpulkan tiga hal pokok yang berkaitan dengan masalah yang dipaparkan sebelumnya. Berikut simpulannya.

1. Strategi kesantunan digunakan dalam talkshow Rumpi (No Secret) meliputi: Bertutur secara terus terang (Bald On Record), bertutur dengan menggunakan kesantunan positif (Positive Politeness Strategy), dengan 11 sub-strategi antara lain; memperhatikan minat penutur, melebihkan minat, dukungan, simpati kepada petutur, meningkatkan ketertarikan terhadap lawan tutur, menggunakan bentuk-bentuk identitas kelompok, mengusahakan persetujuan terhadap lawan tutur, mempraanggapkan sejumlah persamaan penutur dan lawan tutur, menyatakan lelucon, mempraanggapkan bahwa penutur memahami keinginan lawan tuturnya, melibatkan lawan tutur dan penutur dalam suatu kegiatan tertentu, memberi dan meminta alasan. Bertutur dengan menggunakan strategi kesantunan negatif (negative politenes strategy) dengan 3 sub-strategi antara lain; ungkapan secara tidak langsung, menggunakan permohonan maaf. Bertutur dengan menggunakan strategi kesantunan tidak langsung (off record strategy) dengan 4 sub-strategi antara lain; memberi petunjuk, menggunakan kontradiksi, menggunakan ungkapan yang ambigu, menggunakan ungkapan yang tidak 
lengkap. Strategi yang paling sering muncul pada penelitian ini adalah strategi kesantunan positif sebanyak 79 data. Dengan sub-strategi memberikan atau meminta alasan, pembawa acara berusaha menjaga 'muka' positif narasumbernya.

2. Pada pelanggaran prinsip kerja sama dalam talkshow Rumpi (No Secret) di Trans TV, Pelanggaran yang ditemukan oleh penulis meliputi pelanggaran prinsip kerja sama dengan satu maksim, pelanggaran prinsip kerja sama dengan dua maksim dan pelanggaran prinsip kerja sama dengan tiga maksim. Pelanggaran prinsip kerja sama dengan satu maksim antara lain maksim kuantitas, maksim kualitas, maksim relevan, dan maksim cara. Pelanggaran dengan dua maksim antara lain maksim kuantitas dan maksim cara, maksim kualitas dan maksim cara, maksim kuantitas dan maksim relevan, maksim kuantitas dan maksim kualitas, maksim relevan dan maksim cara. Pelanggaran tiga maksim antara lain maksim kuantitas, maksim relevan dan maksim cara; maksim kuantitas, maksim kualitas dan maksim cara; maksim kualitas, maksim relevan dan maksim cara. Pelanggaran prinsip kerja sama yang paling banyak dilanggar oleh narasumber adalah pelanggaran dua maksim yaitu maksim kuantitas dan maksim cara sebanyak 37 data. Pada penelitian ini ditemukan pelanggaran dua maksim yang paling banyak muncul dalam talkshow Rumpi (No Secret) di Trans TV. Pelanggaran dua maksim tersebut adalah maksim kuantitas dan maksim cara, pelanggaran dua maksim terjadi karena narasumber memberikan kontribusi tuturan melebihi yang dibutukan oleh pembawa acara.

3. Sebagai wujud adanya pelanggaran prinsip kerja sama, implikatur yang muncul dalam talkshow Rumpi (No Secret) di Trans TV, antara lain: implikatur belum siap wawancara, menyalahkan, mengkritik, memberitahukan, mengungkapkan kesedihan, menyatakan, melarang, menolak, menyatakan lelucon, menyindir, membenarkan, menjelaskan, bingung, berhati-hati dalam menjawab, mengevaluasi, kesal, mencurigai, dan menegaskan. Implikatur yang paling sering muncul dalam penelitian ini adalah implikatur menjelaskan sebanyak 16 data. 


\section{DAFTAR PUSTAKA}

Brown, P., \& Levinson, S.C. (1987). Politeness some universals in language usage. New York: Cambridge University Press.

Geoffrey, L. (1993). Prinsip-prinsip pragmatik (terjemahan oleh M. D. D. Oka). Jakarta: UI Press.

Kesuma, T.M.J. (2007). Pengantar (metode) penelitian bahasa. Yogyakarta: Penerbit Carasvatibooks.

Rustono. (1991). Pokok-pokok pragmatik. Semarang: IKIP Semarang Press.

Subroto, E.D. (2007). Pengantar Metode Penelitian Linguistik Struktural. Surakarta: Sebelas Maret University Press.

Sudaryanto. (1993). Metode dan aneka teknik analisis bahasa: pengantar penelitian wacana kebudayaan secara linguistik. Yogyakarta: Duta Wacana University Press.

Sutopo, H.B. (1996). Metode penelitian kualitatif: metode untuk ilmu-ilmu sosial dan budaya. Surakarta: UNS Press. 